\title{
WORKPLACE-BASED LEARNING: AN INDUSTRY PERSPECTIVE
}

\author{
R. Ziegler* \\ e-mail: zieglerr@cput.ac.za
}

\section{T. Chipanga*}

e-mail: chipangat@cput.ac.za

\author{
C. Magoda* \\ e-mail: magodac@cput.ac.za
}

*Department of Mechanical Engineering

Cape Peninsula University of Technology

Cape Town, South Africa

\section{ABSTRACT}

Workplace-based learning (WPBL) is a compulsory component of the Mechanical Engineering undergraduate qualification at a South African university of technology (UoT). The Mechanical Engineering students spend a compulsory period of 12 months in industry as part of their undergraduate diploma. However, in response to a national call for curricula revision from the Council on Higher Education (CHE) to align qualifications to the Higher Education Qualifications Sub-Framework (HEQSF), South African higher education institutions embarked on restructuring their qualifications. As a result, the new HEQSF aligned Diploma in Mechanical Engineering (NQF 6) now requires students to spend a reduced period of six months in industry. Given the importance of WPBL in the undergraduate programme, this article focuses on the new reduced period for WPBL and how industry partners view this change. This study draws on data generated through the use of structured questionnaires. One of the outcomes of this study is that industry partners emphasise the importance of the time that students spend in industry and that a reduction in such time will negatively impact on student workplace learning. The perspectives expressed by the industry partners open up avenues for follow-up studies in this regard.

Keywords: work-integrated learning, workplace-based learning, mechanical engineering, curriculum revision, industry partners, undergraduate diploma, university of technology

\section{INTRODUCTION}

The three-year National Diploma Mechanical Engineering students at a South African university of technology (UoT) are required to undergo a mandatory 12-month period of workplace-based learning (WPBL). In this article, WPBL is referred to as a form of workintegrated learning (WIL) where students are attached to an engineering organisation or simulated work environment for purposes of acquiring practical skills and experience. This 
form of WIL, in this instance, involves the placement of students at suitable engineering companies for real-world work experience and training. On-the-job training is implicit in this compulsory component of the undergraduate qualification. The Council on Higher Education (CHE 2011) indicates that WIL is essentially aimed at enhancing student learning. In a similar vein, the Engineering Council of South Africa (ECSA 2015) explains that WIL enhances the students' educational foundations and allows them to gain practical experience. In order to begin their WPBL period, students have to register for the subject Mechanical Engineering Practice, a pre-requisite for obtaining their qualification. This typically takes place after the completion of four semesters of coursework.

Upon successful placement of the students, it is expected that they would be inducted into the workplace culture and that they would receive monitored, contextualised, on-the-job training by industry professionals (qualified technicians, technologists or engineers), who essentially supervise them according to the provided university guidelines and learning outcomes. These guidelines clearly stipulate the expected responsibilities for the UoT, the students and the employers. Student learning activities, the supervision procedure for the employers, ethics and professionalism, expected exit level outcomes, as well as the duration of the learning period, are amongst the guidelines included. Wait and Govender $(2016,280)$ indicate that industry's role here involves the orientation of students, exposure to industry practices, providing educators with feedback on the implementation of WIL and where improvements can be made, in addition to "... being a potential employer of choice". The interactions between the students and the experienced industry professionals are important for learning in the workplace (Tynjälä 2008).

Students are assessed on whether they have competently met all exit level outcomes. Projects, especially design projects, are the preferred method of assessment. The students are provided with industry-based projects for the duration of their WPBL period. They are required to integrate design and manufacturing procedures into the project and submit an engineering project report, in an acceptable format, to the Mechanical Engineering department's cooperative education co-ordinators (now referred to as WIL co-ordinators) and the industry supervisors. These parties jointly assess the final project reports and presentations.

In response to a national call for curriculum revision from the $\mathrm{CHE}$, to align qualifications to the Higher Education Qualifications Sub-Framework (HEQSF), South African higher education institutions embarked on restructuring their qualifications (CHE 2011). There are 26 public universities in South Africa and of these, 11 are traditional universities, nine are comprehensive universities and the remaining six are universities of technology (DHET 2017, 8). Traditional universities, in the old qualifications framework, had 10 NQF levels and the 
UoTs had nine NQF levels of vertical progression that allowed students mobility from one qualification to another. This old framework prevented the mobility of UoT students to traditional and comprehensive universities. The new HEQSF framework provides higher education institutions with an opportunity to align to a single qualifications framework that seeks to establish common parameters and criteria for qualifications design. It facilitates the comparability of qualifications across the higher education system (DHET 2007). The Department of Mechanical Engineering, at the UoT presented in this article, saw an opportunity to critically review and revise its curriculum. The department was especially mindful of some existing gaps in the curriculum that were identified prior to the national call. It sought to bridge the gaps within the field of Mechanical Engineering, between the old and the new qualifications, by introducing new subjects that would provide a better scope of knowledge and progression. One of the gaps identified was linked to content alignment in view of under-preparedness of students entering the Mechanical Engineering programme from high school.

Structural adjustments in the new curriculum reinforce the vocational aspect of the qualification through various WIL modalities. One of the adjustments presented in the new curriculum, with respect to content alignment, was the introduction of Physics and Chemistry fundamentals in the first year, to provide a clear progression of knowledge to the higher level subjects. Furthermore, complementary subjects, such as those that focused on environmental and management aspects, were added. Despite identifying gaps within the existing curriculum, the department could not make any changes prior to the 2011 national call for curriculum revision. Such curriculum revisions can only be effected when a national framework is provided by the Department of Higher Education and Training (DHET) to facilitate such revision, and where all stakeholders, such as the South African Qualifications Authority (SAQA), CHE and ECSA, are consulted.

Decisions on the actual structural curriculum changes, such as the time allocations for WPBL, depended on the individual institutions. Various departments at some institutions opted for either a 240 credit diploma (without WPBL) or a 360 credit diploma (with WPBL). One of the concerns in opting for the 240 credit diploma related to the potential difficulties associated with the placement of students in industries. The placement opportunities for students are few in South Africa and students are unable to graduate in the absence of such placement. This in turn negatively affects the student throughput rate and consequently impacts on the government funding that higher education institutions receive (Mutereko and Wedekind 2015).

The decisions taken by different departments at institutions had to fall within the prescripts of the HEQSF documents. The UoT referred to in this article, opted for the 360 credit diploma (that includes WPBL) in line with the tradition of offering theoretical and practical training. 
The integration of theoretical knowledge with its practical application in the workplace is vital for the Diploma in Mechanical Engineering at the UoT. The aim is to ensure that mechanical engineering students develop the ability to integrate their learning through a combination of academic and work-related activities. The learning time that it would take an average student to meet the expected learning outcomes is measured by the credits allocated. This learning time includes contact time, structured learning, workplace learning, assessment and self-study.

The Department of Mechanical Engineering decided to reduce the time allocated to WPBL from 12 months $(120$ credits $=1200$ notional hours $)$ to six months $(60$ credits $=600$ notional hours) for the new HEQSF aligned Diploma in Mechanical Engineering. One SAQA credit is equivalent to 10 notional hours (SAQA 2014, 8). In the old qualification, the 12-month period for WPBL was assumed to be sufficient time for learning. This period provided students with, amongst others, time to adjust to the workplace and facilitated wider exposure to the workplace environment (depending on the structure of the respective organisations to which students were attached). This WPBL period seemed to have a one-dimensional focus and did not emphasise any other modalities of WIL. The relationship between the duration and the quality of learning was not explicit. Furthermore, the criteria used for the choice of the duration of WPBL was not necessarily informed by any learning theories. According to the ECSA guidelines, a 360 credit diploma must have a minimum of 30 credits for WIL (ECSA 2015, 4). Thus, the 60 credits allocated by the department for WPBL is double the minimum number of credits required by ECSA. The credits are linked to time and quality. In light of maintaining the vocational aspect of the qualification, the reduced WPBL programme is supplemented by other forms of WIL such as project-based learning $(\mathrm{PjBL})$ and problem-based learning $(\mathrm{PBL})$, in addition to a more improved WPBL assessment strategy.

The key differences between the old and the new qualifications offered by the department include: the change in name from National Diploma in Mechanical Engineering to Diploma in Mechanical Engineering, the reduction in credits for WPBL, the change in qualification offering from vocational to both vocational and professional and a less than 50 per cent change in curriculum content. The reasons for the Mechanical Engineering curriculum changes were inter-alia, to create a strong base for further studies through increasing the suite of subjects offered at the diploma level. Furthermore, the changes were made in an attempt to address the difficulties observed in the old curriculum, where students struggled to understand fundamental engineering concepts. Student under-preparedness from the high school education system in meeting the requirements and demands of tertiary engineering education was identified as one of the reasons why they struggled in the previous qualification.

The new HEQSF aligned Diploma in Mechanical Engineering (NQF 6) is primarily 
vocational with some professional aspects. The qualification provides a sound understanding of general theoretical principles as well as a combination of generic and specific procedures and their application (CHE 2011). The professional aspects are reflected in the credits for different knowledge areas developed by ECSA (2015). These knowledge areas and the allocated credits are as follows: Mathematical Sciences (35 credits), Natural Sciences (28 credits), Engineering Sciences (126 credits), Design and Synthesis (28 credits), Computing and Information Technology ( 21 credits), Complementary Studies (14 credits) and Work-integrated Learning (30 credits). These add up to 282 credits with the remaining 78 credits earmarked for redistribution across the knowledge areas. This provides for a more balanced curriculum that will promote horizontal articulation to the vocational and professional Bachelor of Engineering Technology (BEng.Tech) qualification. It is anticipated that the six-month WPBL component of the new Diploma in Mechanical Engineering at the UoT will be implemented for the first time in July 2020.

WIL is recognised for making a significant contribution to the transition of graduates into the workplace and is seen as an important “... bridge for the student between the academic present, and their professional future" (Martin and Hughes 2009, 8). The term WIL manifests in different forms of learning and is defined as the form of learning that encompasses different modalities where theoretical knowledge is integrated with practical skills. WPBL is one of the many different modalities incorporated into WIL. According to Scholtz and Bester (2018), WPBL is referred to as cooperative education or experiential learning where students are placed in industries for a specific period of time for the purposes of integrating theory with practice. $\mathrm{PjBL}$ involves learning through industry-related projects in which supervision is undertaken by the workplace supervisors and the university lecturers. This can either take place in a simulated environment or in the actual workplace. In some instances, WPBL and PjBL can be integrated. The UoT in question has always been at the forefront in seeking to establish and maintain collaborative partnerships with industry, government and community organisations to prepare the workforce of the future. Technological advancements and innovations require higher education institutions to respond accordingly through continuous curriculum development. WPBL requires effective collaboration between institutions of higher learning and industry partners in order to provide a balanced curriculum for students. The participation of strategic stakeholders in curriculum development is recognised as vital in an ever-changing higher education landscape. It is for this reason that this article focuses on the perspectives of Mechanical Engineering advisory board members (industry partners in particular) on the importance of the WPBL time that students spend in the workplace and its impact on student learning. 


\section{LITERATURE REVIEW}

WIL is referred to in the literature as experiential learning (McKune 2013), cooperative education (Wessels 2014), workplace-based experience (Roopnarain and Akoobhai 2014) and work-based learning (Comyn and Brewer 2018; Ebbutt 1996). It is also referred to as an "umbrella term" (Oliver 2015, 60; Reinhard et al. 2016, 251) as it is difficult to define, given the various terms associated with WIL, the contexts in which they are used and the range of workplace learning programmes that they describe. This creates complexities around the use of a common term for all types of academic programmes where learning takes place in the workplace (Comyn and Brewer 2018). It is for these reasons that WIL is sometimes referred to as an "ill-defined concept" (Oliver 2015, 60). According to Webb and Hayes (2008, 1), WIL “... is a form of (practical) education that integrates periods of academic study with periods of work experience in jobs related to the students' study area".

WIL provides an opportunity for valuable partnerships to be forged between institutions, industries and students (Martin and Hughes 2009). Furthermore, WIL is beneficial to both students and employers as highlighted in the literature (Blom 2014; Mutereko and Wedekind 2015). Results from a study by Blicblau, Nelson and Dini (2016) indicate that students who spent longer periods of time in industry obtained better practical skills and were adequately prepared for the working environment. Their study focused specifically on the effect of work placement on engineering students' academic performance, particularly over a short term (over 12 weeks) and a longer term (over 52 weeks). An additional outcome was that some students were offered ongoing employment at the end of their WIL placement period. In a study that compared cooperative learning and WIL in Germany, South Africa and Namibia, Reinhard et al. (2016) report that such student employment opportunities are not unusual, particularly so in the case of UoT students. Employers benefit by having access to employees who are young, still in training, are a low cost to the company and who are potential future employees (Mutereko and Wedekind 2015, 8).

Experience in and exposure to the workplace is an important part of the education process that engineering students undergo, with emphasis placed on the value of such experience (Ahmad 2014). Working in industry, whilst studying, is said to give students a good opportunity to see how engineering relates to the workplace environment (El-Raghy 1998). This opportunity is the result of a relationship between the university, students and industry, referred to as the “triple stakeholder partnership' (Wait and Govender 2016, 280). In this relationship the partners work together to develop student competence and in so doing, make them employable. Student workplace experiences are seen to contribute to their employability (Blom 2014; Harris-Reeves 
and Mahoney 2017). In fact, WIL is seen to contribute to preparing students to become "futurefit graduates", something that is difficult to achieve through education that is classroom-based only (Govender and Wait 2017, 50). It is for this reason that industries have to be aware of the role that WIL plays in the education of the students and supervisors have to be in tune with the university expectations to ensure that the professional competence of the students is correctly measured.

A study by McKune (2013) looked at the effect of experiential learning on the academic performance of Civil Engineering students. It concluded that experiential learning, over a minimum period of six months, is indeed beneficial to students as it positively influences student maturity and their ability to cope with tertiary education. This is particularly evident in students who are academically weaker to begin with. It is understood that WIL provides students with an important platform to learn employability skills and to become more selfconfident. Similar sentiments are shared by Freestone, Thompson and Williams (2006) whose work emphasizes student experiences of work-based learning in planning for university education. They indicate that most of the Australian universities have adopted a one-year period of WIL. The feedback from students and employers indicate that the first six months of the work experience does not fulfil their expectations, but once they are settled into the workplace, the remaining six months yield better performance, an improvement in confidence and students are able to handle more responsibilities. Most importantly, students learn more. However, a study by Jackson (2013) that focused on the role of WIL in enhancing undergraduate employability skills, suggests that student placements in industry do not consistently result in enhanced skills outcomes. Similarly, McNamara (2013) argues that the duration of WIL may not be directly linked to competence. This highlights the need for further research in this area.

In the South African higher education context, Pop and Barkhuizen (2013) investigated the effectiveness of a work-integrated learning programme in contributing to the employability of graduates. Their findings confirm the importance and effectiveness of soft-skills and technical skills training and mentorship in enhancing the employability of graduate interns over a period of 12 months. Their findings also show the importance of having a well-structured WIL programme that seeks to improve mentorship, supervision and assessment.

It is evident that several South African higher education institutions have to meet the changes in higher education by devising strategies to deal with WIL and new ways of incorporating it into the curriculum (Wessels 2014). The perceived impracticalities of implementing WIL (particularly where students are required to be placed in industry), in the South African context, seem to overshadow the potential benefits to students. Mutereko and Wedekind $(2015,2)$ are critical of South Africa for its lack of resources and economic, social 
and institutional policies for not enabling an environment where "an 'ideal' engineering curriculum" can be realised.

\section{METHODOLOGY}

This small scale study made use of a structured questionnaire that was electronically disseminated to Mechanical Engineering advisory board members who were also industry partners. Participation in this study was limited to these members because they offer WPBL opportunities for students in the Mechanical Engineering department. The questionnaire was designed with three specific response areas. The first provided participants with the opportunity to indicate whether the companies that they represented were large, medium or small enterprises. It also required them to specify if these companies were manufacturing, design or maintenance oriented. The second part of the questionnaire provided participants with 14 statements relating to WPBL. These statements were designed using a four point Likert scale that included the following response options: disagree, strongly disagree, agree and strongly agree. Two of the statements provided participants with the opportunity to give reasons for either agreeing or disagreeing with the relevant statements. The last part of the questionnaire gave participants the option to make general comments regarding their views on WPBL. After several written and telephonic reminders, a total of six advisory board members, out of 13, completed the questionnaire. Participation in the study was voluntary and treated as confidential.

\section{FINDINGS AND DISCUSSION}

The findings presented below are intended to provide insight in terms of industry partner perspectives on the reduced time for WPBL. It should be noted that the participants' views expressed in this study, are based on their experiences of WPBL as a 12-month programme for the National Diploma in Mechanical Engineering and what they anticipate from the reduced WPBL period for the new qualification. The responses included herein are presented as verbatim quotations as provided by participants. Of the six participants, two represented large enterprises and four represented medium-sized enterprises. No small enterprises were represented. Their respective companies are involved in engineering-related activities that range from manufacturing, design, maintenance and production. All of the companies represented in this study recruit more than one Mechanical Engineering undergraduate student from the UoT per annum for WPBL. The majority of the participants admit to having offered the Mechanical Engineering students permanent or contract employment after their WPBL period. 
The participants were unanimous in their view that the old National Diploma requirement of a 12-month period for WPBL offers students more time to acquire practical skills and experience, thus making them more employable, compared to the six-month period for the new Diploma in Mechanical Engineering. Furthermore, they believe that a reduction in WPBL time will have a negative impact on achieving all the set learning outcomes and the attainment of associated requirements such as graduate attributes. The majority of the participants are of the view that the new curriculum students will not be afforded sufficient exposure to the world of work in a six-month period. Thus, the industry partners are not in favour of the reduced WPBL period that is offered in the new curriculum and believe that the students will not be adequately assessed within a six-month period. In addition, they are of the view that the reduced WPBL period will undermine and weaken the quality of the student learning experience. They do not agree with the assertion that Mechanical Engineering students who undergo a WPBL period of six months will be as employable as students who undergo a 12-month WPBL period. It is clear from the general participant responses that, in many cases, students who are placed in industry undergo rigorous and systematic induction into the workplace. The experiences and exposure are wide-ranging. As one participant points out, students who are placed in industry are involved in "live" projects and "... engage in various aspects of the business from construction on-site works, manufacturing, design and calculation based works ... project management concepts and associated management systems are taught during all aspects of operational training".

The general responses from the participants suggest that the reduction of time for WPBL is of great concern to them. This relates to, amongst other things, the fact that students enter the workplace with very little, if any, real work experience. As a result, they first have to spend time trying to "find their feet". As one response indicates: "The students only find their feet in the $1^{\text {st }} 6$ months and therefore need to be in the workplace a bit longer". This observation resonates with the findings of Freestone, Thompson and Williams (2006). It is acknowledged that a reduction in time for WPBL may be more acceptable if the students who entered the workplace already had a fair amount of industry experience upon entry. Without sufficient prior work experience, a reduction in WPBL is less agreeable as one participant asserts: "(i)f the student is an Artisan with X-amount years of experience, then I will agree that 6 months will be sufficient, since very little of the exposure to the work environment will be new". This implies that the reduced WPBL period is likely to benefit the more matured, work-experienced students (who are usually in the minority in the undergraduate programme), than the majority of the students who enter the university straight from school.

Students need time to "adjust to the new environment and workplace etiquette and general 
professional conduct". Not only do students require time to acclimatise and orientate themselves in the workplace, they also need time to do the learning that is required in their new environment, outside of the university classroom. The response from one participant suggests that the 12 months allocated to WPBL in the old programme proved to be "tight" in terms of time and that "(r)educing the already tight programme from 12 to 6 months will not allow for sufficient time to learn all that is required". This response is indicative of the view that six months may be impossible to accomplish everything in terms of student learning in the workplace, if the current 12 months is just sufficient.

The responses suggest that the industries where students are placed may have to make certain unfortunate compromises when dealing with the reduction in time allocated for WPBL. Such compromises may inadvertently disadvantage students. For example, students "(w)ill have less experience in all different departments. Only a specific short experience in one or two areas." Important aspects of the WPBL programme may have to be prematurely curtailed or even eliminated, thus depriving the new curriculum students from those workplace experiences and learning opportunities that students in the old curriculum would have been exposed to. Industries would have to adopt different approaches to deal with WPBL and this could lead to approaches that shift from being in-depth to bordering on superficial. As one participant expressed: “(v)ast and incredibly relevant aspects of the learner's training will now be removed from our programme" and that the company "... would either rush through the programme to achieve the coverage of all work areas in a very narrow sense or go into the necessary depth over only a few work areas. Neither option would allow for the level of workplace training which the learner requires and deserves."

WPBL is an active teaching and learning strategy and it would appear that the reduction in time allocated to it is likely to compromise not only the quality of the students' learning experiences in the workplace, but also the development of desired graduate attributes. The time allocated for the required workplace learning activities will not allow for any unintended deviations or flexibility to accommodate for students who might take longer to process information as they learn. Mentors and supervisors in the workplace also need to ascertain individual levels of learning and require time to make adjustments in order to ensure that every student placed receives a fair opportunity for meaningful learning. Consequently, the learning opportunity may be "too rushed" because of the new time allocation. As one participant suggests: "The programme will be too rushed - Should the company or the student fall behind with the programme it will be extremely difficult to make up the time and produce an effective work ready student." This implies that a longer period in the workplace allows for the necessary flexibility and room, when needed, for remedial action on the part of mentors and supervisors. 
Essentially, in the absence of such time, the quality of producing a "work ready student" may be compromised. Another participant's response expresses an acute understanding of the perceived deficiencies that students sometimes enter into the workplace with and what is required from the industry partners in order to assist such students. "More than $60 \%$ of students have not worked a day in their lives and they come from different socio-economic backgrounds. All students are not at the same level when starting out - often an inordinate amount of time is spent to close the gap where there are deficiencies." Furthermore, this suggests that some industry partners are sensitive to the various backgrounds and needs of students and take on the responsibility of attempting to minimise gaps where necessary.

The general sentiment is that "(m)ore time means greater exposure and more learning takes place ..." during a 12-month WPBL period compared to a six-month period. It is not yet clear how the implementation of the new curriculum, with the reduction in WPBL time, will affect the relationship between the various industries and the university. Based on the responses, it could have serious consequences in some cases. One participant points out that the company that he/she represents "... may seriously reconsider the continuation of work place training placement for the engineering students, should the programme now be reduced to 6 months". Another indicates that their company may be "hesitant" in the future "to be associated with the final product" that is produced by the UoT and this implies that they may think twice before employing a graduate that comes to them with a qualification where the WPBL component represents only six months of experience in an engineering workplace. This seems to represent a narrow view of WPBL as being the only form of WIL. Some participants suggest that the students require up to three months to get settled into the work environment. The issue of students settling into the workplace is a valid concern and it can be argued that students are different and therefore the three months" "settling in" threshold may not be conclusive. In other cases (Freestone, Thompson and Williams 2006) students are said to require up to six months just to get settled into the workplace. Theoretically, it is possible for the SAQA 600 notional hours for WPBL to be accommodated in a four-month period. However, whether this will work in practice (after having taken all possible factors into account), needs to be validated by future studies that focus on the time that students take to acclimatise to the work environment where effective and meaningful learning can take place. According to the participants, time spent in the workplace impacts on the quality of learning, skills acquisition, adjustment and exposure to the workplace, and student employability. However, this is not conclusive as a student can spend 12 months in industry and the quality of their learning experience may be poor compared to a student who learns more in a carefully structured environment within six months. Generally, there are many factors that influence workplace learning which further contribute to 
the complexity in achieving the prescribed WPBL outcomes.

\section{CONCLUSION}

It is clear that the participants are not entirely in favour of the new Mechanical Engineering undergraduate curriculum in as far as it relates to the provision of a six-month WPBL period instead of the 12-month period that they have been used to. This is so despite an advisory board meeting where the new curriculum was discussed, with particular reference to the change in the period that students spend in industry for WPBL from 12 months to six months.

The overwhelming sentiment expressed by participants is that students need more than six months in the workplace for various reasons. These include, amongst others, to acclimatise to the new work environment by "finding their feet" and "settling in", to have time for adequate exposure to the many departments and facilities, to become familiar with work responsibilities and simply to have the time to engage in the process of learning that is critical to the students' vocational and professional development. The majority of the participants are of the view that the reduced WPBL period will negatively affect the students in terms of skills acquisition and employability. This remains to be tested once the first student cohort, of the new qualification, graduates.

The current curriculum changes to WPBL will rely on the willingness of industry partners to adjust their workplace programmes to accommodate such changes. Understanding the multimodal nature of workplace learning will require greater collaborative efforts between the UoT and the relevant industry partners. Furthermore, engagements between industries and the UoT will have to be strengthened in order to promote the effective implementation of WPBL.

The authors acknowledge the educational value and experiential benefits of WPBL and believe that its importance should not be undermined in the engineering curriculum. It is also acknowledged that students derive many benefits from a prolonged stay in industry through repetitive work practices. However, well-crafted, student-centred methods and assessment strategies, improved simulated work environments, integrated industry-based projects, laboratories, practicals and workshop activities, in the new six-month WPBL period in the Mechanical Engineering Diploma, can also provide students with meaningful learning experiences. This could potentially benefit both employers and students in the long term, but will have to be carefully monitored and evaluated to see how effective it will be. The authors intend to closely observe the implementation of WPBL in the new qualification and will report on the findings in a follow-up study. 


\section{ACKNOWLEDGEMENTS}

The authors wish to thank all who participated in this study.

\section{REFERENCES}

Ahmad, A. M. 2014. Work based learning is a new dimension in Malaysia tertiary education. International Journal of Accounting \& Business Management 2(1): 17-27.

Blicblau, A. S., T. L. Nelson and K. Dini. 2016. The role of work placement in engineering students' academic performance. Asia-Pacific Journal of Cooperative Education 17(1): 31-43.

Blom, R. 2014. A policy framework for work-integrated learning. The African Journal for Work-Based Learning 2(1): 1-12.

CHE see Council on Higher Education.

Comyn, P. and L. Brewer. 2018. Does work-based learning facilitate transitions to decent work? EMPLOYMENT Working Paper No. 246.

Council on Higher Education. 2011. Work-integrated learning: Good practice guide. HE Monitor No. 12. Pretoria: Council on Higher Education.

DHET see Department of Higher Education and Training.

Department of Higher Education and Training. 2007. The Higher Education Qualifications Framework Act (Act No.101 of 1997). Government Gazette 30353, 5 October (Regulation Gazette No. 928).

Department of Higher Education and Training. 2017. Statistics on post-school education and training in South Africa: 2015. Pretoria: DHET.

Ebbutt, D. 1996. Universities, work-based learning and issues about knowledge. Research in PostCompulsory Education 1(3): 357-372.

ECSA see Engineering Council of South Africa.

El-Raghy, S. 1998. Quality engineering education: Student skills and experiences. Global Journal of Engineering Education 3(1): 25-29.

Engineering Council of South Africa. 2015. New engineering technology qualification standards. Document: E-02-PN, Revision 3. https://www.ecsa.co.za/EcsaDocuments/sitepages/ecsa\%20 documents.aspx\#StandDev

Freestone, R., S. Thompson and P. Williams. 2006. Student experiences of work-based learning in planning education. Journal of Planning Education and Research 26: 237-249.

Govender, C. M. and M. Wait. 2017. Work integrated learning benefits for student career prospects mixed mode analysis. South African Journal of Higher Education 31(5): 49-64.

Harris-Reeves, B. and J. Mahoney. 2017. Brief work-integrated learning opportunities and first-year university students' perceptions of employability and academic performance. Australian Journal of Career Development 26(1): 32-37.

Jackson, D. 2013. The contribution of work-integrated learning to undergraduate employability skill outcomes. Asia-Pacific Journal of Cooperative Education, 14(2): 99-115.

Martin, A. and H. Hughes. 2009. How to make the most of work integrated learning: A guide for students, lecturers and supervisors. Palmerston North: Massey University Press.

McKune, T. 2013. The academic benefit of experiential learning for civil engineering students on the Pietermaritzburg campus of the Durban University of Technology. Proceedings of the Biennial Conference of the South African Society for Engineering Education, Cape Town. 11-12 June, 2013.

McNamara, J. 2013. The challenge of assessing professional competence in work integrated learning. Assessment \& Evaluation in Higher Education 38(2): 183-197.

Mutereko, S. and V. Wedekind. 2015. Work integrated learning for engineering qualifications: A 
spanner in the works? Journal of Education and Work: 1-20.

Oliver, B. 2015. Redefining graduate employability and work-integrated learning: Proposals for effective higher education in disrupted economies. Journal of Teaching and Learning for Graduate Employability 6(1): 56-65.

Pop, C. and N. Barkhuizen. 2013. Exploring the effectiveness of a work-integrated learning programme in contributing towards the employability of graduates: The graduate interns' perspective. The African Journal for Work-Based Learning 1: 28-38.

Reinhard, K., A. Pogrzeba, R. Townsend and C. A. Pop. 2016. A comparative study of cooperative education and work integrated learning in Germany, South Africa, and Namibia. Asia-Pacific Journal of Cooperative Education 17(3): 249-263.

Roopnarain, S. and B. Akoobhai. 2014. Workplace based experience (WBE) - preparing the student for the world of work. The African Journal for Work-Based Learning 2(2): 41-50.

SAQA see South African Qualifications Authority.

Scholtz, D. and M. Bester. 2018. Project-based learning: Panacea for change or old wine in new bottles? South African Journal of Higher Education 32(6): 177-196.

South African Qualifications Authority. 2014. Policy for credit accumulation and transfer within the National Qualifications Framework. Pretoria: SAQA.

Tynjälä, P. 2008. Perspectives into learning at the workplace. Educational Research Review 3: 130154.

Wait, M. and C. M. Govender. 2016. Multi-stakeholder work integrated learning model for higher education - a transdisciplinary approach. South African Journal of Higher Education 30(2): 279293. http://dx.doi.org/10.20853/30-2-585.

Webb, R. M. and J. F. Hayes. 2008 Work integrated learning: Will it work for spatial science wilers? In Proceedings Queensland Spatial Conference, ed. Kevin McDougall, 1-7, Gold Coast, Qld, Australia.

Wessels, M. 2014. Cooperative education at the Tshwane University of Technology: A new direction for work-integrated learning and employability. The African Journal for Work-Based Learning 2(2): $1-15$. 